\title{
Andropause and depression: A perspective for the clinician
}

\author{
Brian Bexton MD FRCPC
}

\section{B Bexton. Andropause and depression: A perspective for the clinician. J Sex Reprod Med 2001;1(2):99-103.}

Major depression and androgen deficiency are both frequent in men older than age 40 years, and the prevalence of both tends to increase with age. In evaluating major depression, clinicians should be aware of this relationship and request laboratory analysis of total and bioavailable testosterone, when indicated. Testosterone replacement therapy can be beneficial in relieving the symptoms of andropause and in increasing a patient's response to antidepressant treatment.

Key Words: Depression; Diagnostic tests; Elderly patients; Familial history; Mental history; Social history

\section{Andropause et dépression : observation pour le clinicien}

RÉSUMÉ : La dépression majeure et la carence en testostérone se rencontrent souvent chez les hommes de plus 40 ans, et la prévalence des deux affections a tendance à augmenter avec l'âge. Aussi les cliniciens devraient-ils tenir compte du lien entre les deux affections lorsqu'ils évaluent des cas de dépression majeure, et demander, s'il y a lieu, une mesure de la testostérone totale et de la testostérone biodisponible. Le traitement de substitution à la testostérone peut s'avérer bénéfique pour soulager les symptômes de l'andropause et accroître la réaction du patient au traitement antidépresseur.
$\mathrm{M}$ enopause in women is a distinct clinical entity with clear signs and symptoms. It is a normal and natural event that usually occurs in women in their fourth and fifth decades of life. Ovarian function ceases, resulting in a significant diminution in estrogen production, anovulation and the cessation of menses.

During the perimenopausal period, women may have physical symptoms, such as hot flushes and decreased vaginal secretions, and they may also experience dysphoria. The incidence of major depression is also increased during the perimenopausal period. Estrogen supplements may decrease dysphoria and can potentiate the effect of antidepressants in major depression.

Andropause is less well-recognized as a clear syndrome in aging men. Unlike menopause in women, men may remain fertile even during their seventh and eighth decades of life. Also, unlike the rapid decreases in hormonal levels in women that occur during menopause, total testosterone levels in men remain more stable over the years.

However, finer analysis shows that the active fraction of testosterone (bioavailable testosterone) decreases progressively after age 40 years. Thus, andropause does not have the same connotation as menopause because hormonal secretions continue. The World Health Organization recognizes the existence of a clinical syndrome characterized by a partial androgen deficiency in aging males.

Thus, the physical and emotional effects of declining hormone secretion in men are less dramatic and less obvious than those experienced by women.

However, in aging men, the syndrome of andropause develops progressively, and may consist of physical, sexual 
and psychological symptoms that include weakness, fatigue, reduced muscle and bone mass, impaired hematopoiesis, oligospermia, sexual dysfunction, depression, anxiety, irritability, insomnia, memory impairment and reduced cognitive function (1).

\section{TESTOSTERONE PHYSIOLOGY}

Both testes and the adrenal glands secrete several male hormones called androgens. Testosterone, the primary androgen, is by far the most abundant and potent. Testosterone production in men is mediated by the hypothalamic-pituitary-gonadol axis. Secretion of gonadotropinreleasing hormone $(\mathrm{GnRH})$ from the hypothalamus stimulates the pituitary gland to release luteinizing hormone, which activates testicular Leydig's cells to produce testosterone. As testosterone concentrations increase, a negative feedback mechanism inhibits the secretion of GnRH. GnRH also stimulates the release of follicle-stimulating hormone, which binds to Sertoli's cells within the seminiferous tubules. Follicle-stimulating hormone enhances spermatogenesis. Testosterone secretion occurs in pulsatile bursts (about six bursts/day), with a morning peak and an early evening trough. In total, approximately $7 \mathrm{mg}$ of testosterone are secreted daily.

Psychological, social, seasonal and biological factors affect testosterone secretion. Levels are elevated at times of decisive victory in competition, when social status is enhanced, during rapid eye movement sleep, after sexual activity, after exercise and during the autumn. They are decreased at times of defeat or submission, during physical or emotional stress, during heavy alcohol use and in the spring. Generally, testosterone levels revert to baseline soon after a stimulus. It is unknown whether a chronic or prolonged stimulus, such as stress occurring during a major depressive episode, can lead to a new testosterone baseline (2).

Testosterone exists in three forms in the blood stream. Only $2 \%$ of the hormone exists unbound as free testosterone. Approximately one-half of testosterone is weakly bound to albumin, and the remainder is tightly bound to sex hormone-binding globulin (SHBG) (2). Bioavailable testosterone refers to non-SHBG-bound forms, including free testosterone and testosterone that is weakly bound to albu$\mathrm{min}$. Bioavailable testosterone is considered to be the biologically active fraction. Between the ages of 40 and 70 years, free testosterone decreases at a rate of approximately $1 \% /$ year. This decline is explained by increasing SHBG concentrations at a rate of $1.2 \%$ /year. As the number of testosterone-binding sites on SHBG increases, the unbound fraction of the hormone decreases. As a result of the declines in both Leydig's cells' function and the sensitivity of the hypothalamic-pituitary-gonadol axis, aging men appear to be unable to compensate for the reduction in circulating testosterone. In fact, $7 \%$ of men aged 40 to 60 years, $20 \%$ of those aged 60 to 80 years, and $35 \%$ of those older than 80 years have total concentrations below the lower limit of normal (350 mg/dL) (3).

\section{EFFECT OF DECREASED TESTOSTERONE LEVELS}

Androgen deficiency in the aging male older than age 40 years may be diagnosed by the following symptoms (4).

- One of the following two symptoms:

- decreased sexual desire; or

- decreased strength of erection.

- Three other symptoms from among the following:

- lack of energy;

- decreased strength and endurance;

- decreased height;

- decreased interest and pleasure;

- impression of being sad;

- decreased capacity to participate in sport activities;

- sleepiness after dinner; and

- a recent decrease in professional performance.

- Decreased bioavailable testosterone.

Many studies have shown a symptomatic improvement after testosterone replacement therapy. The replacement therapy was either intramuscular testosterone enanthate or oral testosterone undecanoate (5).

Compared with baseline, testosterone replacement therapy led to significant decreases in anger, irritability, sadness, tiredness and nervousness, and an improvement in energy levels, friendliness and a sense of well-being. More recent studies have shown improvement in cognitive function in older men (6). However, the relationship between decreased testosterone secretion and major depression is less clear (7).

\section{MAJOR DEPRESSION}

Major depression is a serious illness that affects $5 \%$ of the male population each year, and $17 \%$ of men during their lifetime. The frequency of major depression increases with age and is more frequent after age 40 years, as is decreased testosterone functioning. The diagnosis of major depression can be made using criteria outlined in the Diagnostic and Statistical Manual of Mental Disorders, Fourth Edition: DSM-1V (8), as follows.

- At least five of the following symptoms must be present for at least two weeks:

- depressed mood;

- decreased interest and pleasure;

- loss of appetite and weight (at least $5 \%$ /month; however, atypical depression may result in weight gain);

- insomnia (hypersomnia in atypical depression);

- agitation or psychomotor retardation;

- fatigue and loss of energy;

- feelings of guilt and a loss of value;

- difficulties in concentration; and

- thoughts of death and suicide.

- The above symptoms provoke distress for the 
person, or decrease functioning at a social or work level.

- Symptoms are not related to the use of medication or a substance (eg, alcohol), or medical problems (eg, hypothyroidism).

- Symptoms are not the result of a grieving process.

Major depression tends to have a rapid onset. The patient who has functioned well during the past few months begins to have great trouble functioning with or without a precipiting factor. This scenario differs from the effects of decreasing testosterone levels during andropause, which tend to be more progressive in nature. Also, the depressed patient experiences more negative thinking and more suicidal ideas.

However, if andropause and depression are compared, a number of similar symptoms are evident (Table 1). The physical symptoms of andropause compared with those of depression are listed in Table 2.

Major depression is accompanied by several changes in neurotransmitter levels, as follows.

- Serotonin levels (5-hydroxy-tryptamine) decrease, causing anxiety, depression and increased obsessional thinking.

- Decreased noradrenaline levels are accompanied by a loss of energy and decreased motivation.

- Decreased dopamine levels are associated with decreased pleasure and difficulties in concentration.

Antidepressants function by increasing the concentration of one or more of these neurotransmitters at the synaptic level. Generally, there is a delay of two or three weeks before the neurotransmitters are released. This delay is due to the fact that although antidepressants initially increase the level of neurotransmitters in the synapse, feedback to the presynaptic autoreceptors decreases the release of the neurotransmitters. After two or three weeks, the presynaptic autoreceptors become less sensitive to feedback, and the release of neurotransmitters is increased, which results in the therapeutic effect.

\section{SEXUAL DYSFUNCTION IN DEPRESSION}

Sexual dysfunction in depression may have several causes.

\section{Depression}

Major depression results in a decrease in interest and pleasure. Thus, the male patient may have less desire for sexual activity, and may have difficulty having an erection and achieving orgasm. This is not true for all depressed patients, and some patients are capable of continuing sexual activity.
TABLE 1

Symptoms of andropause and depression that are similar

\begin{tabular}{ll}
\hline Andropause & Depression \\
\hline Dysphoria & Dysphoria \\
Fatigue & Fatigue \\
Difficulties in concentration & Difficulties in concentration \\
Decreased memory & Decreased memory \\
Decreased productivity & Decreased productivity \\
Decreased motivation & Decreased motivation \\
Decreased well-being & Decreased well-being \\
Loss of self-esteem & Loss of self-esteem \\
Increased anxiety & Significant increase in anxiety \\
& and suicidal ideas \\
\hline
\end{tabular}

TABLE 2

Physical symptoms of andropause compared with those of depression

\begin{tabular}{ll}
\hline Andropause & Depression \\
\hline Vasomotors symptoms & $\mathrm{N} / \mathrm{A}$ \\
Decreased strength & $\mathrm{N} / \mathrm{A}$ \\
Decreased endurance & $\mathrm{N} / \mathrm{A}$ \\
Dermatological changes & $\mathrm{N} / \mathrm{A}$ \\
Changes related to aging & $\mathrm{N} / \mathrm{A}$ \\
Physical aches and pains & Aches and pains \\
Decreased libido & Sexual dysfunction \\
Decreased sexual performance & $\mathrm{N} / \mathrm{A}$ \\
Decreased ejaculation & $\mathrm{N} / \mathrm{A}$ \\
\hline
\end{tabular}

N/A Not applicable

\section{Antidepressants}

Certain antidepressants can improve mood, relieve depressive symptoms and, at the same time, produce sexual dysfunction. This is particularly true of antidepressants that act on serotonin levels. Certain tricyclics and selective serotonin reuptake inhibitors (SSRIs), in general, such as fluoxetine (Prozac, Eli Lilly Canada Inc, Canada) and paroxetine (Paxil, SmithKline Beecham, Canada) are frequently associated with sexual dysfunction. These antidepressants increase the level of serotonin (5-HT) in the synapse and stimulate three postsynaptic receptors. Stimulation of $5-\mathrm{HT}_{1 \mathrm{~A}}$ receptors generates a beneficial effect (ie, a decrease in depression, anxiety and obsessional thinking). Stimulation of $5-\mathrm{HT}_{2}$ receptors results in several side effects, including agitation, insomnia and sexual dysfunction. Also, stimulation of $5-\mathrm{HT}_{3}$ receptors may result in other side effects, including gastrointestinal upset and headaches, which may also decrease sexual interest.

If depression has been relieved by an SSRI but there is continued sexual dysfunction, one can consider switching to an antidepressant that will continue $5-\mathrm{HT}_{1 \mathrm{~A}}$ stimulation and block $5-\mathrm{HT}_{2}$ receptors, such as nefazodone (Serzone$5 \mathrm{HT}_{2}$, Bristol-Myers Squibb Canada Inc, Canada) or mirtazapine (Remeron, Organon, Holland). Mirtazapine also blocks $5-\mathrm{HT}_{3}$ receptors, avoiding gastrointestinal upset and 
headaches. Another choice is the use of bupropion (Wellbutrin SR, Glaxo Wellcome Inc, Canada), which increases noradrenaline and dopamine activity but does not affect serotonin transmission. Bupropion is sometimes associated with enhanced sexual function, perhaps related to the increase in dopamine activity.

\section{Androgen deficiency in patients older than age 40 years}

If sexual dysfunction continues after the improvement of mood and depressive symptoms, and despite the switch to an antidepressant that does not cause sexual dysfunction, the clinician should consider that the patient may have an androgen deficiency. Dosages of total and bioavailable testosterone levels will orient the clinician to the possibility of testosterone replacement therapy. If bioavailable testosterone levels are low, prostate-specific antigen (PSA) testing is negative and digital rectal examination is normal, testosterone replacement therapy should seriously be considered (9).

\section{DEPRESSION AND ANDROPAUSE}

Clinicians should remember that depression and andropause may coexist. Thus, treatment of depression does not preclude testosterone replacement therapy. In fact, testosterone replacement can potentiate the effect of antidepressants and result in a more complete response in refractory depression (10).

In refractory depression, the clinical response can be enhanced by combining two antidepressants that act at different sites or by adding different agents that potentiate the effect of antidepressants. Among the possible choices are lithium (in small doses) $\mathrm{T}_{3}$, tryptophane (the precursor of serotonin), anticonvulsants (eg, lamotrigine, Lamictal, Glaxo Wellcome Inc), methylphenidate (Ritalin, Novartis Pharmaceutical Canada Inc, Canada) and estrogen in women during the perimenopausal period. For men with symptoms of andropause, testosterone is a treatment of choice. Patients with recurrent depression, who may have responded well to antidepressants alone in the past, will respond less favourably if the level of bioavailable testosterone is decreased. These hormonal measurements can be part of the routine evaluation in men with sexual dysfunction, loss of physical strength and other symptoms of andropause.

\section{LENGTH OF TREATMENT}

For a first episode of depression, antidepressants are recommended for at least six months and, preferably, one year after the remission of the illness. After a third episode, antidepressants may be given for an indefinite period to prevent relapse. For andropause, long term treatment may also be necessary, with periodic controls of PSA levels and digital rectal examination (9).

\section{CASE PRESENTATIONS}

\section{Case 1}

A 67-year-old man was referred to the author's clinic for refractory depression. The evaluation revealed a history of three depressive episodes in the past, with a good response to tricyclics or a SSRI. The patient had always been active physically and sexually. He had been taking an SSRI for several months with no response. He complained of sleep problems, loss of appetite, a lack of energy, a decline in interest and physical activities, and sexual dysfunction.

At the first visit, the SSRI was stopped and replaced with mirtazapine, which does not interfere with sexual functioning and can rapidly improve sleep and appetite. Laboratory analyses of total testosterone, bioavailable testosterone and PSA levels were requested.

At the follow-up visit, the patient said that he was sleeping better, he had more interest in activities and his mood had improved. However, he still complained of a lack of libido and continued weakness. Laboratory analysis revealed that the total testosterone level was normal, but the bioavailable testosterone level was well below the inferior limit. The PSA level was normal. Testosterone undecanoate was added to the antidepressant treatment.

At the subsequent visit, the patient reported a remission of his depressive symptoms, a gain in physical strength and muscle tone, increased libido and renewed physical activity.

Six months later, his family physician suggested that the patient stop testosterone therapy and have his endocrinological levels re-evaluated.

One month later, the patient reported decreased libido, less physical strength and a more depressed mood. After an endocrinological evaluation, he was restarted on testosterone and, once again, reported improved libido, increased strength and remission of his depressive symptoms.

\section{TESTOSTERONE IS NOT JUST SEXUAL}

Although the emphasis of treating andropause has been on sexual dysfunctioning, androgen deficiency affects other aspects of normal functioning, including decreased energy and muscle strength, depressed mood and loss of interest.

\section{Case 2}

A 59-year-old man was referred to the author's clinic for refractory depression. The evaluation revealed a man with several depressive episodes in the past who had responded well to treatment. The current episode had lasted several months, and he reported a depressed mood, loss of interest, decreased strength, loss of energy and difficulty in completing daily activities.

However, the patient did not report sexual dysfunctioning because he was a member of a religious order and had been celibate all of his adult life. When levels of bioavailable testosterone were determined to be below the inferior limit, the patient was delighted because, as he said, he felt this depression was "different" and he thought that it involved something "physical".

\section{CONCLUSIONS}

Major depression and androgen deficiency are both frequent in men older than age 40 years, and the prevalence of both tends to increase with age. In evaluating major depres- 
sion, clinicians should be aware of this relationship and request laboratory analysis of total and bioavailable testosterone when indicated.

Testosterone replacement therapy can be beneficial in relieving the symptoms of andropause and in increasing a patient's response to antidepressant treatment.

\section{REFERENCES}

1. Sternbach H. Age-associated testosterone decline in men: clinical issues for psychiatry. Am J Psychiatry 1998;155:1310-8.

2. Seidman SN, Walsh BT. Testosterone and depression in aging men. Am J Geriatr Psychiatry 1999;7:18-33.

3. Vermeulen A, Kaufman JM. Aging of the hypothalamuspituitary testicular axis in men. Horm Res 1995;43:25-8.

4. Tremblay RR, Morales A. Canadian practice recommendations for screening, monitoring, and treating men affected by andropause or partial androgen deficiency. Aging Male 1998;1:215-8.
5. Wang C, Alexander G, Berman N, et al. Testosterone replacement therapy improves mood in hypogonadal men: a clinical research center study. J Clin Endocrinol Metab 1996;81:3578-783.

6. Barret-Connor E, Goodman-Gruen D, Patay B. Endogenous sex hormones and cognitive function in older man. J Clin Endocrinol Metab 1999;84:3681-5.

7. Barret-Connor E, Von Mühlen D, Kritz-Silverstein D. Bioavailable testosterone and depressed mood in older men: he Rancho Bernardo Study. J Clin Endocrinol Metab 1999;84:573-7.

8. American Psychiatric Association. Diagnostic and Statistical Manual of Mental Disorders, Fourth Edition, DSM-IV. Washington: American Psychiatric Association, 1994.

9. Morales A, Bain J, Ruijs A, Chapelaine A, Tremblay RR. Clinical practice guidelines for screening and monitoring patients receiving testosterone supplementation therapy. Int J Impot Res 1996;8:95-7.

10. Seidman SN, Rabkin JG. Testosterone replacement therapy for hypogonadal men with SSRI-refractory depression. J Affect Disord 1998;48:157-61. 